\title{
SOB A REESTRUTURAÇÃO PRODUTIVA, ENFERMEIROS, PROFESSORES E MONTADORES DE AUTOMÓVEIS \\ SE ENCONTRAM NO SOFRIMENTO DO TRABALHO
}

\author{
WITH THE RESTRUCTURING OF PRODUCTION PROCESSES, \\ NURSES, TEACHERS AND CAR-ASSEMBLERS SUFFER SIMILAR \\ PRECARIOUS LABOUR CONDITIONS
}

Acacia Zeneida Kuenzer 1

Resumo Este artigo propõe-se a discutir as possibilidades e os limites da intervenção social e da satisfação no trabalho dos profissionais da saúde, buscando compreender em que, nos limites do capitalismo, eles se aproximam dos trabalhadores da educação e dos trabalhadores diretamente produtivos. Para tanto, o texto discute a dupla face do trabalho, enquanto produtor de valores de uso e de valores de troca, relação dialética que compõe uma totalidade por contradição. É essa dupla face que, ao mesmo tempo, nega o humano, ao gerar relações sociais alienantes, e o produz, ao afirmá-lo enquanto indivíduo e enquanto humanidade. No capitalismo contemporâneo, marcado pela acumulação flexível, as demandas por ampliação da qualificação dos profissionais da saúde e da educação acentuam esta contradição com base em uma característica muito peculiar do seu trabalho: a sua natureza não-material. A partir desta discussão, o artigo vai mostrar que, tal como ocorre na educação, a progressiva mercantilização dos serviços na área da saúde, com suas peculiares formas de organização e gestão, se por um lado acentua a dimensão do sofrimento no trabalho, por outro lado também pode potencializar, diante do caráter práxico do trabalho, o desenvolvimento de estratégias de enfrentamento das desigualdades sociais.

Palavras-chave sofrimento do trabalho; mercantilização dos serviços de saúde; reestruturação produtiva; trabalho em saúde; trabalho em educação.
Abstract The objective of this article is to discuss the possibilities and the limits of social intervention and of job satisfaction in the work done by health professionals. Within the boundaries of capitalism, it tries to understand what makes the working conditions of health workers, educational workers and production workers similar, and why. For this purpose, the text discusses the double face of work as a producer of both use values and exchange values, a dialectic relationship that makes up a totality by contradiction. It is this double face that simultaneously denies the human character of the worker, when it creates alienating social relations, and produces it, when it considers him an individual and part of humanity. In contemporary capitalism, marked by flexible accumulation, the demands for better-qualified health and educational workers make this contradiction even greater due to a very peculiar characteristic of their work: its non-material nature. Based on this discussion, the article will show that, as it happens in education, if the progressive commercialization of the health services with its peculiar forms of organization and management - on the one hand, accentuates the dimension of suffering at work, on the other, due to the practical character of the work, it permits the development of strategies in the struggle against social inequalities.

Key words suffering at work; commercialization of the health services; restructuring of the production processes; health work; educational work. 


\section{A dupla face do trabalho}

O trabalho pode ser concebido de duas maneiras: a partir de suas características mais gerais, que independem do modo de produção de mercadorias e que, portanto, são intrínsecas à sua natureza; ou a partir das formas históricas que vai assumindo, de acordo com o desenvolvimento das forças produtivas, ou seja, com base na forma concreta que assume em um determinado modo de produzir mercadorias. Estas duas concepções não se opõem, e sim guardam uma relação dialética entre si, em que, ao mesmo tempo, se negam e se afirmam, configurando a dupla face do trabalho: qualificador, prazeroso e, simultaneamente, desqualificador, explorador, causador de sofrimento.

Para compreender as possibilidades e os limites da intervenção social e da realização profissional e pessoal por meio do trabalho, torna-se necessário caracterizar a relação dialética que configura esta dupla face, como os dois lados da mesma moeda que compõem uma totalidade por contradição.

Em sua concepção geral, o trabalho é o processo através do qual o homem transforma a natureza, os outros homens e a si mesmo, tendo em vista construir as condições necessárias à sua sobrevivência, não apenas como indivíduo, mas também como humanidade (Kuenzer, 1985).

Neste processo, o homem apropria-se da natureza, imprimindo-lhe uma forma que seja útil à vida humana; ele não apenas transforma o material sobre o qual opera, mas conforma-o ao projeto que tinha em mente. É esta característica - a possibilidade de figurar na mente sua construção antes de transformá-la em realidade - que diferencia o trabalho humano do trabalho animal.

Assim, por intermédio do processo de trabalho, a atividade do homem realiza uma transformação sobre o objeto de sua ação, subordinada a um determinado fim: a realização de um produto ou de um serviço para atender necessidades humanas. Uma parte da natureza será adaptada às necessidades do homem, por meio da mudança de sua forma. Este processo produz valores de uso, uma vez que não tem como finalidade produzir excedentes para acumular riqueza. O trabalho, nesta perspectiva, será sempre qualificador, propiciando o exercício da criação, da reflexão e da auto-realização.

Sob o capitalismo, contudo, a característica do processo de trabalho passa a ser a produção de valor de troca, que se auto-expande com a finalidade de acumular riqueza através da produção do trabalho excedente a ser apropriada pelo capitalista. A partir do momento em que o capital detém a propriedade dos meios de produção e da força e trabalho, determina-se o processo de desqualificação do trabalhador, que perde o controle do seu trabalho e das decisões sobre ele e, em decorrência, perde a posse do produto do seu esforço. 
Desta forma, no modo capitalista de produzir, a práxis produtiva cria um mundo de objetos humanizados nos quais o homem não se reconhece, e que se voltam contra ele e o dominam. Esta práxis determina não só uma relação alienante entre o operário e seu produto, mas também entre o trabalhador e os outros homens. Ou seja, relações sociais peculiares, que colocam os homens - produtores e capitalistas - como opositores no processo de produção. Esta alienação ocorre numa relação prática, material, com a natureza, no trabalho, não em sua concepção geral, mas na forma concreta, histórica assumida no capitalismo, não podendo ser reduzida à mera relação sujeito-objeto, uma vez que é resultante de relações sociais.

A desqualificação do trabalhador, conseqüência do trabalho enquanto relação social de produção de valor, decorre da divisão do trabalho, que separa capital e trabalho, trabalho intelectual e trabalho instrumental, dirigente e trabalhador.

Marx, ao longo de sua obra, vai construindo a compreensão desta dupla face do trabalho, em função de sua dupla finalidade: produzir valores de uso e valores de troca. A partir de sua natureza, o autor vai mostrar que, no processo de produção de valor, se o trabalho é a negação do humano ao produzir relações sociais alienantes, esse trabalho produz, ao mesmo tempo, o próprio homem, afirmando-o enquanto indivíduo e enquanto categoria. Este pressuposto fica claro na Ideologia Alemã, quando os autores demonstram que, ao produzir as condições de sua existência, o homem produz-se a si mesmo, elabora conhecimento e produz história (Marx e Engels, s/d, p. 19).

É, portanto, no conjunto de relações determinadas pelo modo de produção da existência, que o homem se faz homem, constituindo-se, de forma concomitante, como determinado por e determinante dessas mesmas relações.

São os mesmos autores que vão mostrar que a produção das idéias, das representações, bem como toda a produção intelectual, está diretamente ligada ao trabalho. Dada esta positividade, como entender a negação da natureza do homem pelo trabalho? Por meio do conceito de objetivação, uma vez que o homem só se manifesta como humano a medida em que concretiza suas forças por intermédio do trabalho, da práxis, que não é um fenômeno individual, mas pressupõe a existência de relações entre os indivíduos. Assim, para realizar sua humanidade, o homem tem de ultrapassar sua subjetividade, através da objetivação, o que ele faz enquanto ser social.

Embora estas forças objetivadas sejam condições necessárias de humanização e, ao mesmo tempo, de negação da humanidade, pelo caráter explorador decorrente da produção de valor para o capital, pode-se afirmar que o homem continua sendo um ser consciente ativo, embora não possa exercitar de forma plena a sua consciência e a sua capacidade criadora. 
É, portanto, por meio do trabalho, que o enfermeiro, como os demais trabalhadores, ao ser submetido pelo capital ao processo de produção de valor - para a própria valorização desse mesmo capital, e não em benefício dos trabalhadores - contribui para a transformação desta mesma realidade, tendo como horizonte a construção de relações sociais mais justas e igualitárias.

Há, ainda, um outro argumento que precisa ser considerado: em que pesem os fatores de alienação, há que considerar que a unidade rompida entre decisão e ação e entre meios de produção e força de trabalho é recomposta no processo de trabalho. Esta característica, além de colocar para o capitalista a necessidade de rigoroso controle, afirma que a geração do excedente depende, também, da capacidade multilateral dos seres humanos, do caráter inteligente e proposital que reveste sua ação de infinita adaptabilidade.

Esta característica é cada vez mais acentuada nas novas formas de organização e gestão do trabalho, onde a fragmentação taylorista-fordista, que atava o trabalhador ao exercício das mesmas ocupações ao longo de sua existência, é substituída por procedimentos mais ampliados. Estes demandam conhecimento da totalidade do trabalho, e não mais apenas da parte, e que simultaneamente ampliam a possibilidade de participação, de decisão e de controle do próprio trabalho, exigindo trabalhadores de novo tipo, com sólida base de educação geral, a partir da qual se construirá uma formação profissional densa e continuada. Embora se saiba que a finalidade do trabalho no capitalismo sempre será a valorização do capital e que este tipo de formação não é para todos - a maioria dos postos tende a ser cada vez mais simplificada, demandando, portanto, trabalhadores desqualificados, realidade que não é diferente na área da saúde - há uma dimensão contraditória que se acentua neste regime de acumulação marcado pela globalização da economia e pela reestruturação produtiva, a partir das demandas de ampliação da qualificação para o exercício profissional.

No caso dos enfermeiros, como o dos professores e demais profissionais liberais, a ampliação se dá a partir de uma característica muito peculiar do seu trabalho: a sua natureza não-material, já que não é possível separar o produtor de seu produto. Essa natureza limita, de certo modo, a realização do trabalho segundo o modo capitalista, que passa a se dar indiretamente, por meio de diferentes mediações que "convençam" o trabalhador, pela força ou pela persuasão, a ser artífice da própria exploração e, ao mesmo tempo, buscar sua realização pessoal, enquanto articulado a uma utopia.

Contudo, é preciso diferenciar 'serviço' enquanto uma expressão para o valor de uso particular de um trabalho ou mesmo para uma troca entre o usuário e o trabalhador - atender a uma pessoa doente, por solidariedade, ou como venda individual de um trabalho sem intermediários - e 'serviço' enquanto expressão de uma relação de compra e venda de força de trabalho 
que se integre ao processo de produção de mercadorias ao gerar um valor excedente que será apropriado pelo capitalista. Em ambos os casos, o trabalho é não-material, não se separando do produtor, e sim expressando relações sociais diferenciadas (Marx, 1978, p. 78). No primeiro caso, uma vez que não há produto material, o enfermeiro atua tal como o artesão, como trabalhador autônomo e independente que vende um trabalho ou serviço, decidindo quando, como fazer e qual o preço; nesta situação, o trabalho tende a ser mais qualificado e mais prazeroso. No segundo caso, o enfermeiro vende sua força de trabalho para uma instituição, que passa a determinar seu trabalho em todas as dimensões, retribuindo-o por meio de um salário; nesta situação, o trabalho tende a ser mais desqualificado, por intermédio da divisão de trabalho nos serviços de saúde, mais intensificado, mais desgastante e, portanto, mais explorado, tendo em vista acumular o capital dos proprietários ou associados, nos casos das cooperativas.

Tal como tem se dado a institucionalização dos serviços de saúde, embora o trabalho mantenha sua característica de não-material, a tendência à sua mercantilização é cada vez mais presente, diminuindo as possibilidades de intervenção criativa e independente dos profissionais da área.

\section{A mercantilização dos serviços de saúde em face das novas formas de organização e gestão do trabalho}

Os serviços de saúde, como os demais, sofreram os impactos da crise do capitalismo no final do século e início deste; forçados a se reoganizar para serem competitivos e assegurarem acumulação, adotaram as estratégias próprias da reestruturação produtiva, neste sentido não se diferenciando das demais empresas, a não ser pela especificidade de seu processo de trabalho. Assim, combinaram complexificação tecnológica com redução de força de trabalho, hierarquizada segundo novas formas de articulação entre qualificação-desqualificação e quantidade de trabalhadores, além de incorporarem mecanismos de descentralização, em particular, a terceirização. Essas novas estratégias levaram à quase extinção da prestação individual de serviços segundo o modelo do artesanato - hoje disponível, como o bom produto artesanal, mediante alto custo - que vem sendo substituído pela institucionalização crescente sustentada por relações de compra e venda de força de trabalho.

Em decorrência, a resistência deste tipo de trabalho não-material (o mesmo ocorre com o trabalho dos professores) a submeter-se às leis da exploração capitalista do trabalho tende a cair por terra, vendendo os profissionais da saúde sua força de trabalho para objetivar um resultado com o qual, na maioria das vezes, não concordam. Através de seu trabalho, objeti- 
vam um produto que é fruto de sua alienação, de sua própria transformação em mercadoria, e não fruto da coincidência entre a sua subjetividade, a sua consciência e as condições materiais de existência, no sentido de utopia, de projeto de transformação da sociedade.

Aos enfermeiros, como aos professores, restaria a esperança de trabalhar nos espaços públicos, onde, em tese, a relação entre custos e benefícios seria regida por outra lógica - a do direito a um serviço público de qualidade - e não pela realização da lógica da mercadoria. Mas nem isto é possível nos Estados de tipo neoliberal, que, ao materializarem a lógica das políticas mínimas, por um lado, empurram sua responsabilidades para o setor privado e, por outro lado, reduzem a política de direitos às ações de filantropia. Essa mesma lógica submete a prestação do serviço público ao compartilhamento com a prestação dos serviços privados, o que impõe que as instituições públicas também sejam regidas pelas leis do mercado. Esta é, inclusive, a nova forma de financiamento dos serviços públicos, que tendem a ser não estatais, concomitantemente ao apequenamento do investimento público estatal, restrito apenas ao financiamento dos absolutamente carentes, que, no Brasil, são os que vivem abaixo da linha da miséria.

Para esta nova institucionalidade dos serviços de saúde, cabem as observações de Gounet (1999) para as empresas reestruturadas, mesmo que seu campo de investigação tenha sido as indústrias automobilísticas, fonte de inspiração para a elaboração teórico-prática das velhas e novas formas de organização do trabalho, tendo em vista a crescente acumulação do capital: o taylorismo-fordismo e o toyotismo.

Este autor, ao estudar as novas formas de organização do trabalho que supostamente ampliariam as demandas de qualificação e as possibilidades de um trabalho mais autônomo e criativo, começa por lembrar que as empresas se reestruturam para acumular, e cada vez mais depressa, por meio de competição com as outras. Isto ocorre porque a demanda não é flexível, dependendo do poder de compra da população, o que vale tanto para vender automóveis quanto para vender serviços de saúde e educação. Portanto, acumular com rapidez significa ampliar o mercado para acumular mais no futuro. Para isto, é importante o que o capitalista faz com o capital acumulado: "mesmo que a escolha tenha implicações sociais, ela é feita por indivíduos, que representam uma minoria, o patronato, e em função de seus interesses próprios" (Gounet, op. cit., p. 41). A tendência das firmas contemporâneas tem sido o reinvestimento no ciclo, estabelecendo-se uma espécie de 'círculo virtuoso', em que as empresas mais lucrativas realizam mais lucros, formando-se grandes e fortes grupos que dominam o mercado e, assim, ditam as leis a seu favor; as demais tendem a desaparecer.

Contudo, o círculo virtuoso, ou a mais-valia que extraem, não é suficiente para manter a liderança no mercado, o que leva estas empresas a bus- 
carem novas estratégias para manter sua posição no mercado. Para tal, podem escolher uma ou combinar várias das seguintes alternativas: buscar fundos públicos ou privados em organismos financeiros internacionais; adquirir novas empresas por incorporação ou fusão; imitar o sistema de produção das empresas líderes; e aumentar a mais-valia extraída na sua produção, automatizando-se, impondo preços mais baixos às subcontratadas, aumentando a exploração dos trabalhadores, acelerando o ritmo de trabalho ou depreciando salários.

Cada uma destas estratégias tem suas limitações, particularmente as que levam as empresas a um grande endividamento, e por isto a implantação de novas formas de organizar e gerir o trabalho pode fazer a diferença em termos de competitividade, desde que se considere que os novos métodos são inseparáveis de um contexto institucional, sociopolítico, próprio de cada país. No Brasil, em especial, nos casos da saúde e da educação, este contexto foi criado pela Reforma do Estado, que viabilizou a privatização de vários serviços antes públicos, a par da concepção do "público não-estatal", que permite novas formas de organização e de financiamento, que são de natureza privada.

Segundo Gounet (op. cit., p. 46), “aceitar não é aderir, é alguma coisa entre a não oposição, o não entrave à instalação do sistema, e a colaboração em alguns casos até ativa", através da cooptação dos trabalhadores e dos sindicatos. Ambos, em muitos casos, passam a assumir a defesa da competitividade da empresa, motivados pela esperança da instauração de uma democracia econômica resultante do discurso do trabalho solidário em equipe e do controle de qualidade feito pelo trabalhador, pelo resgate da dimensão de totalidade do trabalho fragmentado, pela autonomia decisória e, por fim, pela possibilidade do exercício da criatividade e da educação continuada. Pergunta o mesmo autor (p. 47): "será que os patrões tornaram-se subitamente sensíveis ao problema social?". Ao que ele mesmo responde:

"O subitamente indica que não há nenhuma crise de consciência, de arrependimento da exploração imposta aos operários, mas uma estratégia para vencer os concorrentes, encarando seu pessoal não mais como um custo passivo, mas como elemento ativo e essencial da competição". (Gounet, op. cit., p. 47)

De fato, há que considerar que, vistos desta forma, os trabalhadores, e em particular os trabalhadores não materiais, cuja competência resulta de um processo mais longo de qualificação, podem ter aumentado seu poder de negociação por melhores salários e condições de trabalho. Resta saber até que ponto o desemprego estrutural, inclusive dos bem qualificados, não anula esta possibilidade. O fato é que, embora vários autores e o discurso oficial e empresarial no Brasil repitam esta afirmação, a realidade tem mostrado o contrário; ao invés de melhorarem as condições de trabalho, este se 
torna cada vez mais precarizado e intensificado, tanto na saúde e na educação, como na indústria em geral. Isto ocorre porque os ganhos de produtividade são criados pelo aumento da exploração do trabalho, seja ele vivo, incorporado ao trabalhador, ou morto, incorporado à maquinaria.

Vários estudos já mostram que a tendência das novas formas de organização e gestão do trabalho é a sua crescente precarização e intensificação (Kuenzer, 2001; Gounet, 1999).

Alguns aspectos, à guisa de exemplificação, podem ser citados. Do ponto de vista do emprego, convive-se com um processo que pode ser chamado de 'exclusão includente', por meio do qual o mercado formal exclui para reincorporar em formas mais precárias, seja com salários mais baixos no emprego formal, seja através do trabalho terceirizado, domiciliar, infantil, e até mesmo semi-escravo (Kuenzer, 2001).

Gounet demonstra que a 'flexibilização', ao introduzir a multitarefa, ao invés de tornar o trabalho mais interessante e qualificado, o intensifica, passando um trabalhador a ter de desempenhar tarefas que antes eram da responsabilidade de vários trabalhadores. No Brasil, estabeleceu-se uma versão peculiar do banco de horas: quando não há trabalho, os trabalhadores são dispensados, repondo as horas quando a produção assim o exigir, ocasião em que excederá a jornada de trabalho e trabalhará nos finais de semana sem receber horas extras. Em casos limite, são contratados trabalhadores temporários para atender a demandas específicas da produção; diga-se, de passagem, que existem cadastros de temporários que sempre são chamados, configurando-se uma nova categoria: porém, os 'temporários permanentes', que fazem, quando necessário, o mesmo trabalho que os demais, não têm direitos.

Outro dado a observar é que, em decorrência da diminuição de trabalhadores em nome da flexibilização, há sobrecarga de trabalho que tende a aumentar com o tempo, demandando uma nova modalidade de gerenciamento: by stress, o que significa acelerar o fluxo para que os problemas que permanecem latentes em situação normal, apareçam e possam ser solucionados, assegurando a competitividade da empresa. Da mesma forma, para trabalhar em equipe e ser polivalente, o trabalhador precisa, de fato, ser melhor qualificado, porém os trabalhadores não têm seus salários aumentados, configurando-se uma superexploração de mais-valia, responsável por boa parte dos ganhos de produtividade da empresa (Gounet, op. cit., pp. 29-30).

\section{Por que os trabalhadores aceitam o sofrimento no trabalho?}

No item anterior, buscou-se evidenciar que, a partir da mercantilização dos serviços de saúde, os trabalhadores deste setor não se diferenciam dos demais, em termos de sua superexploração, em face da valorização do capital. 
Do ponto de vista do sofrimento no trabalho, há questões que precisam ser apontadas para discussão e pesquisa: a natureza não-material do trabalho do cuidador, que o submete a mais sofrimento, em face do que se torna mais vulnerável às doenças ocupacionais, e em especial, à síndrome da desistência, chamada por Codo 'burnout' (Codo, 1999); as razões que levam os trabalhadores a se submeter pacificamente e ainda justificar o sofrimento no trabalho, na linha que vem sendo discutida por Dejours (1999); e, finalmente, as possibilidades e limites de realização profissional e intervenção social pelo trabalho. Sem pretender aprofundar estas questões, mas apenas pontuá-las para debate, serão rapidamente apresentadas algumas conclusões dos estudos destes autores.

Codo coordenou uma grande pesquisa, financiada pela Confederação dos Trabalhadores da Educação (CNTE), justamente para melhor compreender o conflito entre o trabalho do professor como possibilidade de transformação social e as limitações que lhe são impostas, particularmente a partir das novas formas de materialização do trabalho no âmbito da reestruturação produtiva. Como a pesquisa se refere, de modo geral, aos problemas de trabalho enfrentados pelos cuidadores, suas conclusões permitem melhor compreender o trabalho dos enfermeiros e demais profissionais da saúde.

Para o autor, a síndrome de burnout pode ser definida como

"A dor de um profissional encalacrado entre o que pode fazer e o que efetivamente consegue fazer, entre o céu de possibilidades e o inferno dos limites estruturais, entre a vitória e a frustração; é a síndrome de um trabalho que voltou a ser trabalho mas que ainda não deixou de ser mercadoria" (Codo, op. cit., p. 13).

A concepção do autor remete à discussão levada a efeito nos itens anteriores deste texto: o trabalho do enfermeiro, como o do professor, se objetiva na tensão entre trabalho em geral, qualificador, transformador, prazeroso, e trabalho capitalista, mercadoria comprada para valorizar o capital. Esta tensão se acentua pelo caráter não-material destes trabalhos, que não permite sua separação do produtor, o que, por um lado, reafirma o espaço da consciência e da subjetividade e, assim, o poder do trabalhador, ao mesmo tempo que, cada vez mais, o elimina, em face da crescente objetivação decorrente da progressiva institucionalização dos serviços de saúde. Neste sentido, a natureza do processo de acumulação do capital diminui os espaços de intervenção do trabalhador.

A tensão, portanto, entre objetividade e subjetividade é uma das relações estudadas por Codo no trabalho do cuidador. O cuidado, para o autor, é "uma relação entre dois seres humanos cuja ação de um resulta no bem estar do outro" (op. cit., p. 52). Esta relação configura uma manifestação do trabalho em geral, na medida em que supõe um processo de transformação 
de dupla mão: naquele que cuida e naquele que recebe o cuidado, ambos aprendendo um com o outro, em face de determinadas circunstâncias que demandam ações, decisões e reflexões. No entanto, a medida em que o cuidador vende seu trabalho como mercadoria, estabelecem-se algumas limitações à realização plena da relação sujeito-objeto, uma vez que as ações possíveis estarão definidas pelo tipo de trabalho, por sua duração e pelas demais especificações definidas em um contrato de trabalho, mesmo que informal. Nas atividades dos cuidadores, o estabelecimento de relações, a criação de vínculos, é uma condição necessária; no entanto, como essas relações, enquanto trabalho assalariado, são mediadas pelo contrato, nunca se realizam satisfatoriamente, criando contradições que não permitem o completo retorno das energias dispendidas, no sentido da satisfação no trabalho; ou seja, o produtor jamais chega a se reconhecer no produto, como o artesão em sua obra. No final do ano, o aluno sai da escola e o professor raramente terá o retorno do seu trabalho; da mesma forma, o paciente tem alta ou vai a óbito.

Assim, a relação entre sujeito e objeto nunca se completa, ficando inconclusa a obra, trazendo sofrimento e não realização. Ou, como afirma Codo, "as mediações que a profissionalização do cuidado impõem criam uma tensão entre vincular-se versus não vincular-se, onde o circuito da relação homem-objeto não pode ser completado de forma satisfatória" (op. cit., p. 53). De modo geral, a tendência é o não envolvimento como forma de evitar sofrimento, uma vez que a ação do cuidador será sempre limitada pela natureza do seu trabalho e de suas formas de organização: normas, programas, prescrições e cronogramas.

Esta contradição, parte da natureza do trabalho não-material, que não se objetiva em um produto, mas apenas presta um serviço, é uma das condições que podem trazer sofrimento e não realização, se não for adequadamente enfrentada, quer pela qualificação dos cuidadores, quer pelas formas saudáveis de organização do trabalho. Esta dimensão, específica do trabalho não-material, aliada a outras, típicas de todas as formas de assalariamento (baixos salários, condições precárias de trabalho, intensificação, estresse, medo de perder emprego, autoritarismo e outras) podem causar a síndrome da desistência, que envolve esgotamento emocional, desenvolvimento de atitudes negativas em relação ao trabalho, falta de envolvimento pessoal no trabalho e assim por diante (Codo, op. cit., p. 238). É importante, portanto, compreender por que os profissionais da saúde e da educação desistem, e como melhorar suas possibilidades de realização no trabalho.

O fato que se observa é que, quanto mais se ampliam as necessidades de professores e profissionais da saúde, mais crescem as impossibilidades de realização profissional e de intervenção social desses profissionais, dos quais muito se exige e que muito exigem de si mesmos. Mas, se muitos de- 
sistem, acometidos pela síndrome de burnout, outros permanecem lutando, apesar das dificuldades, buscando formas de humanizar o trabalho, de abrir espaços para decisões não conformes com as regras e de criar novas soluções; e, assim, se realizam e intervêm positivamente pelo trabalho, transformando a realidade.

Aqui se coloca, portanto, o contido na terceira tese de Marx sobre Feuerbach: a transformação da realidade depende da coincidência da transformação das circunstâncias e das consciências (Marx e Engels, s/d). Ou, elaborando de outro modo a questão, que circunstâncias formam subjetividades que permanecem lutando e que circunstâncias formam subjetividades que se submetem à dominação, a justificam ou desistem?

Embora ainda não se tenha suficiente pesquisa para elucidar esta indagação, há trabalhos que apontam as novas formas de organização e gestão do trabalho, demarcadas pela globalização da economia, pela reestruturação produtiva e pelo neoliberalismo, como responsáveis pela formação de novas subjetividades marcadas pelo individualismo, pelo hedonismo e pela competitividade que se submetem ao sofrimento ético, que praticam ações que contrariam seus princípios éticos e até as justificam, em nome do atingimento de suas metas pessoais.

Este é o objeto de estudo de Dejours, que parte da análise do sofrimento nas situações comuns de trabalho, para examinar como tantas pessoas de bem participam de sistemas de gestão que se baseiam na "utilização sistemática da ameaça e numa estratégia eficaz de distorção da comunicação" (1999, p. 139), repetindo as mentiras até que pareçam e sejam aceitas como verdade.

Afirma o autor que a novidade não está na existência de um sistema injusto, comum ao longo da história, mas no fato de um sistema que produz e agrava injustiças e desigualdades ser apresentado como bom e justo, ou seja, a novidade é "a banalização das condutas injustas que lhe constituem a trama", concebendo-a como o processo capaz de atenuar a consciência moral em face do sofrimento imposto a outros e criando um estado de tolerância ao mal (Dejours, op. cit. p. 139). Ou seja, apesar de continuar centrado na dominação do trabalho e na apropriação das riquezas que este produz, o neoliberalismo é apresentado como um sistema capaz de diminuir as desigualdades e injustiças produzidas pela contradição entre capital e trabalho.

A forma pela qual o neoliberalismo conduz à banalização da injustiça social é o medo ou a insegurança da perda do emprego, da precarização do trabalho, da perda de qualidade de vida, da impossibilidade de sustentar a família, submetendo-se à racionalidade ética, à racionalidade estratégica, e tendo como conseqüências a desmobilização coletiva e a aceitação de práticas injustas como se fossem justas. Ou seja, são as condições objetivas que produzem subjetividades que, em nome de seus interesses individuais, ate- 
nuam sua indignação contra a injustiça e o mal, "desdramatizando-o" (p. 138).

Isto significa, pergunta Dejours, que o trabalho seja essencialmente uma máquina para produzir o mal e a injustiça? Claro que não, como também já se discutiu na primeira parte do texto, ao se configurar a dupla face do trabalho. Embora o trabalho seja cada vez mais simplificado, desumanizado e precarizado no neoliberalismo, ele também é o mediador insubstituível da formação humana, na perspectiva da construção do homem enquanto indivíduo e enquanto humanidade e, neste sentido, fundamento do conhecimento e da história. Há que considerar, portanto, que a práxis é também potencialmente transformadora das condições de injustiça e exploração humana. Embora mostre Dejours que não há ação sem trabalho, e não há ambos sem sofrimento, também não há ação sem paixão. Ainda não temos os elementos necessários à compreensão do porquê muitos trabalhadores da saúde e da educação, apesar das circunstâncias agravadas pelo neoliberalismo, se organizam, reagem e resistem, humanizando o trabalho e lutando para a transformação da realidade desigual e injusta. Contudo, é certo que, em algum momento de suas trajetórias, acendeu-se, por força da feliz coincidência entre formação das consciências em dadas circunstâncias, a chama da utopia que faz o trabalho grávido de múltiplas possibilidades de realização pessoal como resultado da intervenção social.

\section{Notas}

1 Professora Titular do Setor de Educação da Universidade Federal do Paraná, pesquisadora da área de Educação e Trabalho. Doutora em Educação pela PUC/SP. <acaci azk@uol.com.br>

2 Texto elaborado a partir de conferência realizada no 53o. Congresso Brasileiro de Enfermagem - CBEn, realizado em Curitiba, Pr, de 9 a 14 de outubro de 2001, publicado com autorização dos organizadores. 


\section{Referências bibliográficas}

CODO, W. 1999. Educação: carinho e trabalho. Rio de Janeiro: Vozes.

DEJOURS, C. 1999. A banalização da injustiça social. Rio de Janeiro: Fundação Getúlio Vargas.

GOUNET, T. 1999. Fordismo e Toyotismo na civilização do automóvel. Campinas: Boitempo.

KUENZER, A. 1985. Pedagogia da Fábrica. São Paulo: Cortez.
KUENZER, A. no prelo. Exclusão includente e inclusão excludente: a nova forma de dualidade estrutural nas novas relações entre educação e trabalho.

Anais do V Seminário Nacional de Estudos e Pesquisas - HISTEDBR, Campinas, UNICAMP.

MARX e ENGELS, s/d. Ideologia Alemã. Lisboa: Martins Fontes.

MARX, K. 1978. O Capital. Livro 1, Capitulo VI inédito. São Paulo: Ed. Ciências Humanas. 